\title{
Determinants of Anemia among Pregnant Women at Debre Tabor Comprehensive and Specialized Hospital
}

\author{
Gashaw Mehiret Wubet \\ Debre Tabor University, College of Health science, School of Medicine, Debre Tabor, Ethiopia \\ Email: mehiretg21stdr@gmail.com
}

How to cite this paper: Wubet, G.M. (2021) Determinants of Anemia among Pregnant Women at Debre Tabor Comprehensive and Specialized Hospital. Open Journal of Blood Diseases, 11, 105-119.

https://doi.org/10.4236/ojbd.2021.114011

Received: August 22, 2021

Accepted: October 12, 2021

Published: October 15, 2021

Copyright (อ 2021 by author(s) and Scientific Research Publishing Inc. This work is licensed under the Creative Commons Attribution International License (CC BY 4.0).

http://creativecommons.org/licenses/by/4.0/

\section{(c) (i) Open Access}

\begin{abstract}
Background: Anemia is one of the most occurring nutritional deficiency problems in the world especially in Africa. It can be prevalent in women of reproductive age, particularly during pregnancy when it is often a contributory cause of maternal mortality. In our country Ethiopia, anemia prevalence is increased from 2011 to 2016 in all anemia categories. Even though scarce information is known about the problem in Ethiopia and studies related to the problem are not available at Debre Tabor comprehensive and specialized hospitals. Hence, we aimed to assess the prevalence and factors associated with anemia among pregnant women who are attending antenatal care at Debre Tabor Comprehensive and specialized hospitals. Methods: Institutionbased cross-sectional study was conducted from October 15 to November 15, 2020 , with a sample size of 232 pregnant women participants selected using a systematic random sampling method. Laboratory determination of hemoglobin level was done at Anti-natal care follow-up. The data was entered into Epi info Version 7.2 and exported to SPSSS version 23 for analysis. Descriptive statistics using frequency and other summary statistics were used to present the socio-demographic and clinical characteristics of women. Binary and multivariable logistic regression was done to identify factors associated with anemia using an odds ratio at $95 \% \mathrm{CI}$ and $\mathrm{p}$-value $<0.05$ significance level. Result: The magnitude of anemia showed that $12.9 \%$ with $95 \%$ CI $(9.4 \%$ $17.7 \%)$. The mean age of the participants was 33 years with a range of $18-39$ years. Rural residency (AOR: 2.82; 95\% CI: $1.02-4.87$, p-0.001), multi-parity were (AOR: 3.12; 95\% CI: 2.43 - 7.56, p-0.045), previous malaria attack (AOR: 1.91; 95\% CI: $1.04-4.88$, p-0.023), and having history of abortion (AOR: 2.10; 95\% CI: 1.18 - 6.79, p-0.014) were factors associated to anemia in pregnancy. Conclusion: This study found a relatively high magnitude of anemia among pregnant women. Rural residency, multi-parity, previous malaria attack, and having a history of abortion were found to be independent predictors of
\end{abstract}


anemia in pregnancy.

\section{Keywords}

Magnitude, Anemia, Pregnant Women, Contributing Factors, Ethiopia

\section{Background}

Anemia in pregnancy is defined when the distribution of hemoglobin ( $\mathrm{Hgb})$ level is below the fifth percentile. The cut-off value varies by trimester during pregnancy. It has been determined anemia as Hgb level of less than $11 \mathrm{gm} / \mathrm{dl}(\mathrm{Hct}<$ $33 \%)$ in the first trimester and third trimester, and less than $10.5 \mathrm{gm} / \mathrm{dl}(\mathrm{Hct}<$ $32 \%)$ in the second trimester [1].

Anemia during pregnancy is considered severe when the hemoglobin value is less than $7.0 \mathrm{~g} / \mathrm{dL}$, moderate when hemoglobin falls between $7.0-9.9 \mathrm{~g} / \mathrm{d}$, and mild from $10.0-11 \mathrm{~g} / \mathrm{dL}$ [2]. Anemia during pregnancy is a major cause of morbidity and mortality of pregnant women in developing countries and has both maternal and fetal consequences [2].

Anemia is a disorder characterized by a blood hemoglobin concentration lower than the defined normal level and usually related to the decrease in the circulating mass of red blood cells. This may result from reduced generation of red blood cells, or from their premature destruction or loss through chronic blood loss. It is one of the most frequently observed nutritional deficiency diseases in the world today. It is especially prevalent in women of reproductive age, particularly during pregnancy [3] [4]. During pregnancy, with the growth of the fetus and the placenta, the larger amount of circulating blood in the expectant mother leads to an increase in the demand for nutrients, especially iron and folic acid [5].

It is one of the frequently occurring nutritional deficiency diseases observed globally and affects more than 1.62 billion (25\%) people of the world's population, of which 56 million are pregnant women [6]. Anemia is a major public health problem affecting all ages of the world's population. It is estimated that anemia causes $>115,000$ maternal and 591,000 perinatal deaths globally per year [6].

Although the prevalence of anemia is estimated at $9 \%$ in countries with high development, in countries with low development the prevalence is $43 \%$. Children and women of reproductive age are most at risk, with global anemia prevalence estimates of $47 \%$ in children younger than 5 years, $42 \%$ in pregnant women, and 30\% in nonpregnant women aged 15 - 49 years and in Africa and Asia accounting for more than $85 \%$ of the absolute anemia burden in high risk groups [1] [7]. In Ethiopia, anemia prevalence among women age 15 - 49 decreased from $27 \%$ in 2005 to $17 \%$ in 2011 but then increased again to $24 \%$ in 2016; these data suggest that anemia is a moderate public health problem [8] [9]. Increases were observed from 2011 to 2016 in all anemia categories [10]. In normal preg- 
nancy, there is a decrement of about $5 \mathrm{gm} / \mathrm{dl}$ in the hemoglobin concentration. Due to the disproportionate increase in plasma volume with respect to the red cell mass. This occurs mostly in the second and third trimesters and is not pathologic in itself, but could precipitate any anemia already present. Based on the above reasons, the World Health Organization (WHO) has supported antenatal oral supplement of iron and folic acid for the prevention of anemia in pregnancy [11] [12]. The cost in hospital treatment of cases of severe anemia is also far outweighed the cost of prophylactic measures [13] [14].

In light of this deficit, the need of conducting this study is to determine the prevalence of anemia in women following antenatal care (ANC) at DTCSH and to identify the major associated factors, which potentially influence pregnant women at high risk of developing anemia.

\section{Methods and Materials}

\subsection{Study Design and Period}

Government health institutions based cross-sectional study was employed from October 15 to November 15, 2020.

\subsection{Study Area}

The studies were carried out at Debre Tabor Comprehensive and specialized hospitals. Debre Tabor is located north east of Amhara Region of Ethiopia, 103 km from Bahir Dar (Regional Capital) and $666 \mathrm{Km}$ from Addis Ababa (National Capital).

\subsection{Source Population}

All pregnant women attended the antenatal care clinic in Debre Tabor Comprehensive and specialized hospital during the study period.

\subsection{Study Population}

All pregnant women attending the antenatal clinic of Debre Tabor Comprehensive and specialized hospital during the study period fulfilled the criteria.

\subsection{Inclusion Criteria}

Pregnant women who came for ANC follow-up during the study period were included in the study.

\subsection{Exclusion Criteria}

Pregnant women who are seriously ill and were already receiving anemia treatment during the survey were excluded.

\subsection{Sample Size and Sampling Technique}

\subsubsection{Sample Size Determination}

Sample size was calculated depending on a single population proportion formula 
by using: 95\% confident interval, 5\% margin of error, and $16.6 \%$ proportion based on the results found on research done at Gondar in2013 and by adding a $10 \%$ nonresponse rate.

The final sample size calculated in Epi info version 232.

\subsubsection{Sampling Procedure}

Systematic random sampling technique was employed in these cases. Average number of pregnant women attending $\mathrm{MCH}$ clinic of DCSH in 1 month duration is, 275 were divided to the allocated sample size is 232 to get the interval ( $\mathrm{K}$ value $=0.84-1)$, that is one, and then the lottery method used to get the random starter. And then every other pregnant woman was interviewed until the allocated sample size was achieved.

\subsection{Data Collection}

The data were collected from October 15, 2020 to November 15, 2020. The questionnaires were written in English including interviews of all subjects, physical examination, and laboratory investigation. The hemoglobin level was determined using Sahli hemoglobin meter. Microscope was used for stool examination; and all laboratory investigations were done by a laboratory technician as part of their routine activity.

\section{Data Processing and Analysis Procedures}

Before and during data processing, the information was checked for completeness and internal consistency. Data was coded and entered using EPI info version 7.2 and exported to SPSS version 23 for further analysis. The analysis was verified using descriptive statistics interpretation for demographic, socio-economic, and clinical characteristics of the study participants using frequencies and other summary statistics. Binary logistic regressions were used to measure the association of each covariate with the outcome variables. In addition, factors that were associated with the outcome variables at p-value $<0.05$ significance level were included in the multivariable logistic regression analysis to control the potential confounders. The result of the final model was expressed in terms of Adjusted Odds Ratio (AOR) and 95\% confidence intervals (CI) and statistical significance was declared at p-value less than 0.05 .

\section{Result}

\subsection{Sociodemographic Characteristics of Pregnant Women}

A total of 232 pregnant women who had ANC visits at Debre Tabor Compressive and specialized Hospital were participated in the study which were achieving $100 \%$ response rate. Around half $(46.6 \%)$ of the respondents were in the age range of 26 to 35 years and almost all (97\%) were Amhara in ethnicity, and more than 90\% were Orthodox Christians regarding religion. Two-hundred seventeen $(93.5 \%)$ of the attendees were married but only Twelve (5.2\%) were single. Re- 
garding educational status, 106 (45.7\%) of the attendees achieved secondary school and above, but 53 (22.8\%) of the participants were no formal education. Majority of them had a higher level of income status (more than 1000 ETB per month) (Table 1).

\subsection{Obstetric and Gynecological History}

One hundred fifty-seven (67.7\%) of the ANC attendees respondents had history of pregnancy. Of those who had a history of pregnancy, twenty-four $(10.3 \%)$ of them had at least one history of abortion. Of those who had a history of birth, one hundred sixty (68.9\%) had a birth intervals of two or more years between the last and the current pregnancy. Majority of the ANC attendees, 179 (77.2\%), had history of contraceptive use prior to current pregnancy. Eighty two (35.5\%) of the respondents had a history of menstrual irregularity. Regarding gestational age, 45 (19.4\%), 63 (27.2\%), and $134(57.8 \%)$ were in first, second, and third trimester of pregnancy, respectively (Table 2 ).

Table 1. Sociodemographic characteristics of ANC attendees in Debre tabor compressive and specialized hospital, North central Ethiopia, from October 15 to November 15, 2020 $(\mathrm{n}=232)$.

\begin{tabular}{|c|c|c|c|}
\hline & Variables & Frequency & Percentage \\
\hline \multirow{5}{*}{$\begin{array}{c}\text { Age at } \\
\text { pregnancy in years }\end{array}$} & $<30$ years & 147 & $63.4 \%$ \\
\hline & $\geq 30$ years & 85 & $36.6 \%$ \\
\hline & $18-25$ & 102 & $43.9 \%$ \\
\hline & $26-35$ & 108 & $46.6 \%$ \\
\hline & Greater than or equal to 36 & 22 & $9.5 \%$ \\
\hline \multirow{2}{*}{ Residence } & Urban & 164 & $70.7 \%$ \\
\hline & Rural & 68 & $29.3 \%$ \\
\hline \multirow{3}{*}{ Ethnicity } & Oromo & 1 & $0.4 \%$ \\
\hline & Amhara & 225 & $96.9 \%$ \\
\hline & Tigre & 6 & $2.6 \%$ \\
\hline \multirow{3}{*}{ Marital status } & Married & 217 & $93.5 \%$ \\
\hline & Single & 12 & $5.2 \%$ \\
\hline & divorced & 3 & $1.3 \%$ \\
\hline \multirow{3}{*}{ Religion } & Muslim & 15 & $6.5 \%$ \\
\hline & Orthodox & 215 & $92.7 \%$ \\
\hline & Protestant & 2 & $0.9 \%$ \\
\hline \multirow{3}{*}{ Educational status } & Illiterate & 53 & $22.8 \%$ \\
\hline & Primary school & 73 & $31.5 \%$ \\
\hline & Secondary school and above & 106 & $45.7 \%$ \\
\hline \multirow{2}{*}{ Income } & $300-1000$ ETB & 32 & $13.8 \%$ \\
\hline & more than $1000 \mathrm{ETB}$ & 200 & $86.2 \%$ \\
\hline
\end{tabular}


Table 2. Obstetrics and gynecology related characteristics among ANC attendees in DTCSH, north central Ethiopia, from October 15 to November 15, $2020(\mathrm{n}=232)$.

\begin{tabular}{|c|c|c|c|}
\hline \multicolumn{2}{|r|}{ Variables } & \multirow{2}{*}{$\begin{array}{c}\text { Frequency } \\
75\end{array}$} & \multirow{2}{*}{$\begin{array}{c}\text { Percentage } \\
32.3 \%\end{array}$} \\
\hline \multirow{3}{*}{$\begin{array}{c}\text { Number of } \\
\text { previous deliveries }\end{array}$} & Nulliparous & & \\
\hline & $1-4$ & 135 & $58.2 \%$ \\
\hline & Greater than or equal to 5 & 22 & $9.5 \%$ \\
\hline \multirow{2}{*}{ History of abortion } & Yes & 24 & $10.3 \%$ \\
\hline & No & 208 & $89.7 \%$ \\
\hline \multirow{2}{*}{$\begin{array}{l}\text { Contraceptive use prior } \\
\text { to current pregnancy }\end{array}$} & Yes & 179 & $77.2 \%$ \\
\hline & No & 53 & $22.8 \%$ \\
\hline \multirow{2}{*}{$\begin{array}{l}\text { Birth interval } \\
\text { from index child }\end{array}$} & Less than 2 year & 14 & $6.0 \%$ \\
\hline & Greater than or equal to 2 year & 160 & $68.9 \%$ \\
\hline \multirow{2}{*}{$\begin{array}{l}\text { History of menstrual } \\
\text { irregularities }\end{array}$} & Yes & 82 & $35.3 \%$ \\
\hline & No & 150 & $64.7 \%$ \\
\hline \multirow{3}{*}{$\begin{array}{l}\text { Gestational } \\
\text { age in weeks }\end{array}$} & less than or equal to 12 week & 45 & $19.4 \%$ \\
\hline & 13 - 24 week & 63 & $27.2 \%$ \\
\hline & greater than or equal to 25 week & 134 & $57.8 \%$ \\
\hline \multirow{2}{*}{$\begin{array}{l}\text { History of using } \\
\text { contraceptives }\end{array}$} & Yes & 183 & $78.9 \%$ \\
\hline & No & 49 & $21.1 \%$ \\
\hline \multirow{4}{*}{$\begin{array}{c}\text { Type of } \\
\text { contraceptive } \\
\text { women used } \\
(n=183)\end{array}$} & Injectable & 131 & $71.6 \%$ \\
\hline & Pills & 34 & $18.6 \%$ \\
\hline & Loop/IUCD & 16 & $8.7 \%$ \\
\hline & Others & 2 & $1.1 \%$ \\
\hline
\end{tabular}

\subsection{Medical Illness, Behavioral and Nutritional History}

Only nine (3.9\%) of the participants had a history of malaria attack in the last one year. Twenty (8.6\%) of them had a history of chronic medical illnesses and the common type of chronic illness was tuberculosis, accounting for $40 \%$ of them. One hundred and ninety-four (83.6\%) of them wear shoes and only three mothers never wore shoes. None of the respondents had a history of avoiding any type of food during this pregnancy. Almost all respondents (97.8\%) were using iron during the current pregnancy (Table 3 ).

Among the participants, nine (50\%) of the participants had a history of hookworm attack in the last one year. Three (17\%) of them had a history of giardiasis illnesses and the rest of the intestinal parasitoids were Entamoeba histolytic, accounting for 6 (33\%) of them (Figure 1).

\subsection{Magnitude of Anemia among Pregnant Women}

Among the total of two hundred thirty-two (232) pregnant women who participated 


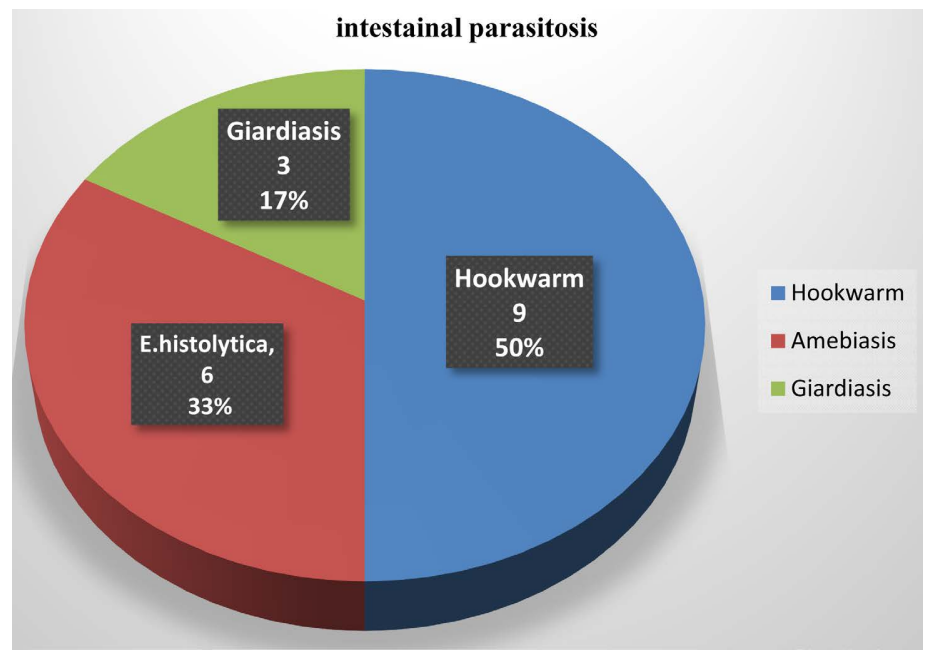

Figure 1. Distribution of intestinal parasitoids among pregnant women in Debre Tabor Comprehensive and specialized Hospital, North central Ethiopia, 2020.

Table 3. Medical, behavioral, and nutritional characteristics of ANC attendees in DTCSH, North central Ethiopia, from October 15 to November 15, $2020(n=232)$.

\begin{tabular}{|c|c|c|c|}
\hline Variables & & Frequency & Percentage \\
\hline \multirow{2}{*}{ Malaria attack in the past 12 months } & Yes & 9 & $3.9 \%$ \\
\hline & No & 223 & $96.1 \%$ \\
\hline \multirow{5}{*}{ History of chronic illnesses } & Tuberculosis & 8 & $3.4 \%$ \\
\hline & HIV & 5 & $2.2 \%$ \\
\hline & Renal disease & 4 & $1.7 \%$ \\
\hline & Others & 3 & $1.3 \%$ \\
\hline & None & 212 & $9.4 \%$ \\
\hline \multirow{3}{*}{ Shoes wearing habit } & Always & 194 & $83.6 \%$ \\
\hline & Sometimes & 35 & $15.1 \%$ \\
\hline & None & 3 & $1.3 \%$ \\
\hline \multirow{2}{*}{ Food avoided during pregnancy } & Yes & 202 & $87.1 \%$ \\
\hline & No & 30 & $12.9 \%$ \\
\hline \multirow{2}{*}{ Intestinal Parasitoids } & Yes & 18 & $7.6 \%$ \\
\hline & No & 214 & $92.2 \%$ \\
\hline
\end{tabular}

in this study, thirty (12.9\%) of them were anemic (hemoglobin $<11 \mathrm{~g} / \mathrm{dl}$ ). From those who were anemic, the majority, twenty-five (83.3\%), were mild (hemoglobin values $10-10.9 \mathrm{~g} / \mathrm{dl}$ ) and five (16.6\%) were moderately anemic (hemoglobin values of $7-9.9 \mathrm{~g} / \mathrm{dl})$.

\subsection{Contributing Factors to Anemia in Pregnant Women}

In the multivariable analysis, pregnant women who were from rural residence 
were 2.8 times more likely to have anemia than urban residence (AOR: 2.82 ; $95 \%$ CI: 1.02, 4.87, p-0.001). Pregnant women whose income $<1000$ ETB were 7 times more likely to have anemia compared to those with high monthly family income (greater than 1000 Ethiopian Birr), (AOR: 7.23; 95\% CI: 4.65 - 26.58, p < 0.001). Pregnant women who have a history of malaria in the past 12 months were 1.9 times more likely to have anemia than urban no malaria attack (AOR: 1.91; 95\% CI: 1.04, 4.88, p-0.023). Pregnant women who have Parity $\geq 4$ children were 3 times more likely to have anemia than those who have less than four children (AOR: 3.12; 95\% CI: 2.43 - 7.56, p-0.045). Pregnant women who have a history of abortion were 3 times more likely to have a history of Anemia than their counterparts (AOR: 2.10; 95\% CI: 1.18 - 6.79, p-0.014) (Table 4).

\section{Discussion}

This study assessed the magnitude of anemia and its contributing factors among pregnant women attending ANC in Debre Tabor Comprehensive and specialized hospital in north central Ethiopia. The overall magnitude of anemia among pregnant women attending ANC was found to be $12.9 \%$, which is lower than a study conducted in some countries such as West Africa (66\%), Singapore (81\%) or Peru (70\%). Many studies in Africa reported a high prevalence of anemia [11] [15].

Magnitude was also lower compared to the study done at JUSH MCH clinic (38.2\%) and government health institutions of Arba Minch town (32.8\%) and

Table 4. Multivariable analysis showing the contributing factors for anemia among pregnant women attending ANC in DTCSH, North central Ethiopia, from October 15 to November 15, $2020(\mathrm{n}=232)$.

\begin{tabular}{|c|c|c|c|c|c|c|}
\hline \multirow{2}{*}{ Variables } & & \multicolumn{2}{|c|}{ Presence of anemia } & \multirow{2}{*}{ COR (95\% CI) } & \multirow{2}{*}{$\operatorname{AOR}(95 \% \mathrm{CI})$} & \multirow{2}{*}{$\mathrm{p}$ value } \\
\hline & & Yes & No & & & \\
\hline \multirow{2}{*}{ Age at pregnancy } & $<30$ & $61(41.5 \%)$ & $86(58.5 \%)$ & 1 & 1 & \multirow{2}{*}{0.067} \\
\hline & $\geq 30$ & $48(56.5 \%)$ & $37(43.5 \%)$ & $1.83(1.07,3.14)$ & $1.01(0.31,2.89)$ & \\
\hline \multirow{2}{*}{ Residence } & Urban & $67(40.8 \%)$ & 97 (59.2\%) & 1 & 1 & \multirow{2}{*}{0.0001} \\
\hline & Rural & $47(69.2 \%)$ & $21(30.8 \%)$ & $3.20(1.78,5.91)$ & $2.82(1.02,4.87)$ & \\
\hline \multirow{2}{*}{ Educational status } & Illiterate & $36(67.9 \%)$ & $17(32.1 \%)$ & $3.22(1.68,6.17)$ & $1.23(0.54,3.69)$ & \multirow{2}{*}{0.178} \\
\hline & Literate & $71(39.7 \%)$ & $108(60.3 \%)$ & 1 & 1 & \\
\hline \multirow{2}{*}{ Income } & $<1000$ ETB & $16(50 \%)$ & $16(50 \%)$ & $13.28(5.51,32.05)$ & $7.23(4.65,26.58)$ & \multirow{2}{*}{$<0.001$} \\
\hline & $\geq 1000$ ETB & $14(7.0 \%)$ & $186(93 \%)$ & 1 & 1 & \\
\hline \multirow{2}{*}{$\begin{array}{l}\text { History of malaria } \\
\text { in the past } 12 \text { months }\end{array}$} & Yes & $27(65.9 \%)$ & $14(34.2 \%)$ & $2.92(1.44,5.99)$ & $1.91(1.04,4.88)$ & \multirow{2}{*}{0.023} \\
\hline & No & $76(39.8 \%)$ & $115(60.2 \%)$ & 1 & 1 & \\
\hline \multirow{2}{*}{ Parity } & $<4$ children & $32(25 \%)$ & $96(75 \%)$ & 1 & 1 & \multirow{2}{*}{0.045} \\
\hline & $\geq 4$ children & $67(64.4 \%)$ & $37(34.6 \%)$ & $5.43(3.08,9.58)$ & $3.12(2.43,7.56)$ & \\
\hline \multirow{2}{*}{ History of abortion } & Yes & $15(62.5 \%)$ & $9(37.5 \%)$ & $3.02(1.26,7.25)$ & $2.10(1.18,6.79)$ & \multirow{2}{*}{0.014} \\
\hline & No & $74(35.6 \%)$ & $134(64.4 \%)$ & 1 & 1 & \\
\hline
\end{tabular}


slightly lower compared to the study conducted at Gondar University Hospital (16.6\%) [16]. This difference could be due to geographical variation of factors across different areas and may be due to time gap between the current study and the other studies, this discrepancy also occurred due to methodology used by the researcher. In addition, the lower magnitude can be attributed to the gradual improvement of the life style of the participants and changing of living standards and health seeking behavior by the effort of government policy.

In the current study, among pregnant women, mild anemia was found to be the commonest type. Consistent result was reported from studies conducted in government health institutions of Arba Minch town and Gondar University Hospital [4] [7]. This could be due to similar social-demographic factors and similar study design conducted.

Rural residence had a higher association with high magnitude of anemia among pregnant women who attended ANC in Debre Tabor Comprehensive and specialized Hospital ( $\mathrm{p}$ value $\leq 0.001,95 \% \mathrm{CI} ; 0.056,0.303$ ). This was consistent with the study done at Bisidimo Hospital in Southeast Ethiopia [3]. The higher magnitude of anemia among pregnant women from rural areas is likely related to lack of awareness about adequate nutrition during pregnancy, economic factors, and inaccessibility of health care facilities [17] [18].

Magnitude of Anemia had also significant association with literacy status (AOR: $1.23(95 \%$ CI: $1.72-9.44$, p value $=0.001)$ ). This result was comparable with the study done in Jimma town health institutions [19]. This may be resulted from most uneducated mothers, which are less likely to use family planning and repeated delivery, thus will have more blood loss during delivery, and there will be no time to restore already depleted iron stores and they have less awareness and knowledge about nutrition during pregnancy hence anemia results [20].

Monthly income was significantly associated with anemia in pregnancy ( $\mathrm{p}$ value $\leq 0.001,95 \%$ CI; 0.031, 0.182). Pregnant women who had low monthly family income (less than 1000 Ethiopian Birr) were more likely to be anemic compared to those with high monthly family income (greater than 1000 Ethiopian Birr). This is in congruent with the study conducted in government health institutions of Arba Minch town and Gondar University Hospital [7] [8]. This could be explained by that pregnant women in low-income groups could not get adequate nutrition so that they were at risk of anemia [21].

The presence of malaria attack in the past one year had contributed to the magnitude of anemia during pregnancy (AOR: 1.91 (95\% CI: $1.04-4.88$, p value $=0.023)$ ). In this study, nine of the pregnant women had a history of malaria attack in the past one year. This result is an agreement with the study done at Bisidimo Hospital in Southeast Ethiopia and Aymiba Health Center, northwest Ethiopia [6] [22]. This association could be due to malaria causing anemia by destroying RBCs at a rate faster than the body can replace them.

Pregnant women's who had five or more previous deliveries (grand multipara) had a significant contributing to the magnitude of anemia (AOR: 3.12 (95\% 
CI: $2.43-7.56, \mathrm{p}$ value $=0.045)$ ). This result is comparable with the study done at Gondar University Hospital and Jimma town health institutions [19] [23]. This significant association may be due to grand multipara women's were less likely to use family planning, and they had more blood loss during delivery, and there will be no time to restore already depleted iron stores and hence anemia results.

In our study, hookworm infestation has increased the risk of being anemic in pregnant women's ( $\mathrm{p}$ value $=0.001,95 \% \mathrm{CI} ; 0.025,0.402$ ) and this finding was consistent with other studies like Bisidimo Hospital in Southeast Ethiopia and Gilgel Gibe Dam area, southwestern Ethiopia [8] [22]. This is because adult hookworm parasites attach and injure the upper intestinal mucosa and ingest blood. This brings about gastrointestinal blood loss and induces depletion of iron, folic acid, and vitamin B12 that ultimately causes anemia.

In this study, pregnant women's who had a history of abortion had contributing with the occurrence of anemia during pregnancy (AOR: 2.10 (95\% CI: 1.18 6.79 , $\mathrm{p}$ value $=0.014)$ ). And this finding is comparable with the study done at Jimma town health institutions [21]. This contribution may be due to more blood loss during abortion and there will be no time to recover already depleted iron stores and this leads to the development of anemia [24].

The present study showed no significant association between anemia and maternal age, ethnicity, marital status, religion, contraceptive use, shoe wearing habits, birth interval, chronic medical illness, menstrual irregularities, iron supplementation and gestational age.

\section{Study Limitations}

Though our study tried to identified important factors of anemia, other factors, such as other nutritional deficiencies (like folate, vitamin B12, and others), inherited or acquired disorders which affect hemoglobin synthesis, red blood cell production or red blood cell survival, which can all cause anemia, were not addressed.

\section{Conclusion}

The overall magnitude of anemia in our study among women attending ANC at Debre Tabor comprehensive and specialized hospital in Debre Tabor town was low and mild anemia is the commonest. Anemia was a mild public health problem in the study area, which is less than the national prevalence. Address, monthly income, parity, educational status, history of abortion, malaria attack history, and hook warm infestation were associated with anemia. Therefore there is a need to provide proper health education for all reproductive age women about the prevention of identified factors of anemia.

\section{Acknowledgements}

We are grateful to the cooperation of the hospital staffs, data collectors, and par- 
ticipants for their co-operation during data collection.

\section{Ethics Approval and Consent to Participate}

An ethical approval was obtained from the research ethics committee of Debre Tabor University. Following the endorsement by the research ethics committee, the selected hospitals were informed about the study through a support letter. Informed verbal consent was obtained from the study participants, which was approved by the Research Ethics Committee of Debre Tabor University, and this study was conducted in accordance with the Declaration of Helsinki. Confidentiality of information and privacy of participants' interview was respected.

\section{Availability of Data and Materials}

The data for this study will be obtained from the cross ponding author on a reasonable request.

\section{Conflicts of Interest}

The author declared as there is no competing of interest.

\section{Author's Contributions}

The authors made significant contributions to the conception and design, acquisition of data, or analysis and interpretation of data; they also took part in drafting the manuscript and agreed with the journal to which the article has been submitted. All authors approved the final version of the manuscript to be published; and agree to be accountable for all aspects of the work.

\section{References}

[1] Control, C.f.D. and Prevention (2010) Pediatric and Pregnancy Nutrition Surveillance System. What Is PedNSS/PNSS.

[2] Addis, A.K. and Mohamed, D.A. (2014) Prevalence of Anemia and Associated Factors among Pregnant Women in an Urban Area of Eastern Ethiopia. Anemia, 2014, Article ID: 561567. https://doi.org/10.1155/2014/561567

[3] Kejela, G., et al. (2020) Prevalence of Anemia and Its Associated Factors among Pregnant Women Attending Antenatal Care Follow Up at Wollega University Referral Hospital, Western Ethiopia. Contraception and Reproductive Medicine, 5, 1-8. https://doi.org/10.1186/s40834-020-00130-9

[4] McMahon, L.P. (2010) Iron Deficiency in Pregnancy. Obstetric Medicine, 3, 17-24. https://doi.org/10.1258/om.2010.100004

[5] Gulliford, M. (2002) Oxford Textbook of Public Health. Oxford University Press, Oxford.

[6] Asrie, F. (2017) Prevalence of Anemia and Its Associated Factors among Pregnant Women Receiving Antenatal Care at Aymiba Health Center, Northwest Ethiopia. Journal of Blood Medicine, 8, 35. https://doi.org/10.2147/JBM.S134932

[7] Bekele, A., Tilahun, M. and Mekuria, A. (2016) Prevalence of Anemia and Its Associated Factors among Pregnant Women Attending Antenatal Care in Health Institutions of Arba Minch Town, Gamo Gofa Zone, Ethiopia: A Cross-Sectional Study. 
Anemia, 2016, Article ID: 1073192. https://doi.org/10.1155/2016/1073192

[8] Melku, M., et al. (2014) Prevalence and Predictors of Maternal Anemia during Pregnancy in Gondar, Northwest Ethiopia: An Institutional Based Cross-Sectional Study. Anemia, 2014, Article ID: 108593. https://doi.org/10.1155/2014/108593

[9] Ibrahim, S.P. (2012) Maternal Anaemia and Perinatal Outcome in Plateau State Specialist Hospital, Jos, North Central Nigeria. Faculty of Family Medicine.

[10] Amsalu, E.T., Akalu, T.Y. and Gelaye, K.A. (2019) Spatial Distribution and Determinants of Acute Respiratory Infection among Under-Five Children in Ethiopia: Ethiopian Demographic Health Survey 2016. PLoS ONE, 14, e0215572.

https://doi.org/10.1371/journal.pone.0215572

[11] Zijp, I.M., Korver, O. and Tijburg, L.B. (2000) Effect of Tea and Other Dietary Factors on Iron Absorption. Critical Reviews in Food Science and Nutrition, 40, 371-398. https://doi.org/10.1080/10408690091189194

[12] Gudeta, T.A., Regassa, T.M. and Belay, A.S. (2019) Magnitude and Factors Associated with Anemia among Pregnant Women Attending Antenatal Care in Bench Maji, Keffa and Sheka Zones of Public Hospitals, Southwest, Ethiopia, 2018: A Cross-Sectional Study. PLOS ONE, 14, e0225148. https://doi.org/10.1371/journal.pone.0225148

[13] Fujimori, E., et al. (1999) Iron Nutritional Status in Pregnant Adolescents, Sao Paulo, Brazil. Archivos Latinoamericanos de Nutricion, 49, 8-12.

[14] Obse, N., Mossie, A. and Gobena, T. (2013) Magnitude of Anemia and Associated Risk Factors among Pregnant Women Attending Antenatal Care in Shalla Woreda, West Arsi Zone, Oromia Region, Ethiopia. Ethiopian Journal of Health Sciences, 23, 165-173.

[15] Shaaban, H.A. (2015) The Factors Contributing to Secondary School Adolescent Pregnancy and Its Impacts in Tanzania: A Case of Dodoma Municipality. The University of Dodoma, Dodoma.

[16] Takele, W.W., et al. (2018) Anemia among Women Attending Antenatal Care at the University of Gondar Comprehensive Specialized Referral Hospital, Northwest Ethiopia, 2017. Anemia.

[17] Isandu, A.O. (2010) Prevalence and Determinants of Anaemia in Pregnant Women Attending Antenatal Clinic in Jos, Plateau State, Nigeria. Faculty of Family Medicine.

[18] Alflah, Y.M., et al. (2017) Prevalence and Determinants of Anemia in Pregnancy, Sana'a, Yemen. International Journal of Public Health Science, 6, 213-220. https://doi.org/10.11591/ijphs.v6i3.7931

[19] Wartanowicz, M., et al. (2001) Assessment of Nutritional Folate Status and Selected Vitamin Status of Women of Childbearing Age. European Journal of Clinical Nutrition, 55, 743-747. https://doi.org/10.1038/sj.ejcn.1601217

[20] Kefiyalew, F., et al. (2014) Anemia among Pregnant Women in Southeast Ethiopia: Prevalence, Severity and Associated Risk Factors. BMC Research Notes, 7, 771. https://doi.org/10.1186/1756-0500-7-771

[21] Getachew, M., et al. (2012) Anaemia and Associated Risk Factors among Pregnant Women in Gilgel Gibe Dam Area, Southwest Ethiopia. Parasites \& Vectors, 5, 296. https://doi.org/10.1186/1756-3305-5-296

[22] Belachew, T. and Legesse, Y. (2006) Risk Factors for Anemia among Pregnant Women Attending Antenatal Clinic at Jimma University Hospital, Southwest Ethiopia. Ethiopian Medical Journal, 44, 211-220.

[23] Fei, C.Z. (2018) Prevalence of Anemia and Its Associated Factors among Female 
Vegetarians in Kuala Lumpur and Selangor, Malaysia.

[24] Agboghoroma, C.O., Sagay, S.A. and Ikechebelu, J.I. (2013) Nigerian Prevention of Mother to Child Transmission of Human Immunodeficiency Virus Program: The Journey So Far. Journal of HIV and Human Reproduction, 1, 1.

https://doi.org/10.4103/2321-9157.116527 


\section{Annex}

\section{DEBRE TABOR UNIVERSITY}

College of health science

Questioner Format

Questionnaire to assess the Determinants of Anemia among pregnant women at Debre Tabor Comprehensive and Specialized Hospital

\section{IDENTIFICATION}
1. Age years
2. Address
A. Urban B. Rural
3. Ethnicity
A. Oromo B. Amhara
C. Tigre D. Others
4. Marital status
A. Married B. single
C. Divorced D. widowed
5. Religion
A. Muslim C. Protestant E. Others
B. Orthodox D. Catholic
6. Educational status
A. Illiterate B. Primary School
C. Secondary school and above
7. Family income (Birr per month)

8. Do you have attack of malaria in the last 12 months?

A. Yes B. No

9. Do you use contraceptive prior to this pregnancy?

A. yes B. No

10. If yes for No. 9, which type?
A. Pills B. Injectable C.
C. loop (IUCD)
D. Others

11. Number of previous deliveries

A. live birth B. still birth

C. none

12. Do you have any history of abortion?

A. yes B. No

13. If yes for No.12, total number of abortion

14. How often do you wear shoes?

A. Always B. Sometimes C. none

15. Do you have any food that you don't eat during pregnancy?

A. Yes B. No

16. If yes for No 15, why?

17. Birth interval from index child (months/years)

18. History of chronic illnesses

A. Tuberculosis C. Renal disease 
B. HIV D. Others, specify

19 Did you have menstrual irregularities?

A. Yes B. No

20 . When was your last menstrual period? (E.C), Gestational age weeks

21. Fundal height weeks

22. Laboratory results;

A. Stool examination

B. Hemoglobin $\mathrm{gm} / \mathrm{dl}$

\section{Abbreviations and Acronyms}

ANC = Antenatal care; HCT = Hematocrit; Hgb = Hemoglobin; IDA = Iron deficiency Anemia; DTCSH = Debre Tabor Comprehensive and Specialized hospital; $\mathrm{WHO}=$ world health organization; JUSH = Jimma University specialized hospital; $\mathrm{MCH}=$ Maternal and child health; $\mathrm{CBE}=$ Community based education; AIDS = Acquired immune deficiency syndrome. 